\title{
Can we diagnose isolated, exercise-induced heart failure with normal ejection fraction?
}

\author{
Jaroslav Meluzinn ${ }^{\mathrm{a}, \mathrm{b}}$, Zdenka Gregorova ${ }^{\mathrm{a}, \mathrm{b}}$, Monika Spinarovaa, ${ }^{\mathrm{a}, \mathrm{b}}$, Roman Panovsky ${ }^{\mathrm{a}, \mathrm{b}}$
}

\begin{abstract}
Background. A significant proportion of patients with exertional dyspnea require exercise to diagnose heart failure with normal ejection fraction (HFNEF).

Methods and Results. In this review article, we evaluate current data on the prevalence, clinical significance and specifically the establishment of a diagnosis of isolated, exercise-induced HFNEF. Despite the unquestioned clinical importance and high prevalence of exercise-induced HFNEF, there are limited and conflicting data on making a diagnosis of exercise-induced HFNEF. This mostly relies on the evidence of exercise-induced elevation in left ventricular filling pressure (LVFP). At present, there is no agreement on the ability of exercise echocardiographic parameteres to predict exercise-induced LVFP elevation. In addition, even invasively measured exercise LVFP faces the problem of defining normal exercise LVFP values. More data and probably new diagnostic approaches are necessary to reliably diagnose exercise HFNEF.
\end{abstract}

Conclusions. There are conflicting results and significant problems associated with the diagnosis of exercise HFNEF. This review hopefully will encourage further research in this difficult but clinically important area of heart failure.

Key words: exercise echocardiography, left ventricular filling pressure, heart failure with normal ejection fraction

Received: September 23, 2014; Accepted: December 19, 2014; Available online: February 10, 2015

http://dx.doi.org/10.5507/bp.2014.066

${ }^{a}$ Department of Cardiovascular Diseases, St. Anne's University Hospital, ICRC, Brno, Czech Republic

${ }^{b}$ Department of Cardiovascular Diseases, Masaryk University, Brno, Czech Republic

Corresponding author: Jaroslav Meluzin, e-mail:jaroslav.meluzin@fnusa.cz

\section{INTRODUCTION}

It is estimated that $1-2 \%$ of the adult population in developed countries has heart failure ${ }^{1}$. Of heart failure patients, approximately $30-50 \%$ have a normal left ventricular ejection fraction (LVEF) $\left(\right.$ ref. $\left.^{2-5}\right)$, i.e. they suffer from heart failure with normal ejection fraction (HFNEF). The proportion of patients with a diagnosis of HFNEF is increasing $^{4,5}$ and is significantly higher among community patients than among referral patients ${ }^{4}$. The survival rate of these patients is comparable ${ }^{3}$ or slightly better ${ }^{4}$ than those with reduced LVEF, but the mortality of patients with HFNEF is still high and represents a serious prob$1 \mathrm{em}{ }^{4}$. Early and correct diagnosis of HFNEF as well as proper follow-up and treatment may form important steps in an effort to prolong a patient's life and/or to improve its quality.

\section{DIAGNOSIS OF HEART FAILURE WITH NORMAL EJECTION FRACTION}

Criteria for the diagnosis of HFNEF include the presence of signs and symptoms of heart failure, presence of normal or mildly abnormal left ventricular (LV) systolic function (ejection fraction $>50 \%$ at $\mathrm{LV}$ end-diastolic volume index $<97 \mathrm{~mL} / \mathrm{m}^{2}$ ) and evidence of diastolic LV dysfunction and/or structural myocardial changes such as LV hypertrophy or left atrial dilation ${ }^{1,6}$. Evidence of diastolic dysfunction relies mainly on the finding of elevated left ventricular filling pressure (LVFP), obtained by invasive (pulmonary capillary wedge pressure $>12 \mathrm{mmHg}$, left ventricular end-diastolic pressure $>16 \mathrm{mmHg}$ ) or noninvasive measurements ${ }^{6}$. Of the noninvasive methods, echocardiography plays a pivotal role in assessing diastolic function and in predicting LVFP. A noninvasive estimate of LVFP elevation is derived from pulsed-wave Doppler recording of the peak early diastolic transmitral flow velocity (E) and from Doppler tissue imaging of the peak early diastolic mitral annular velocity (e'). Figures 1 and 2 depict Doppler recording of transmitral LV filling flow showing E velocity and Doppler recording of mitral annular motion at the septal corner demonstrating e' velocity. The ratio of $\mathrm{E} / \mathrm{e}^{\prime}>15$ is suggestive of LVFP elevation and is diagnostic of HFNEF. In the E/e' ratio, e' is calculated as an average of early diastolic mitral annular velocities measured at septal and lateral corners. If the $\mathrm{E} / \mathrm{e}$ ' ratio is in the range of 8-15, the presence of at least one other marker associated with diastolic dysfunction (disturbed transmitral filling and/or pulmonary venous flow, LV hypertrophy, left atrial dilation, presence of atrial fibrillation or natriuretic peptide elevation) is required to diagnose HFNEF (ref. ${ }^{6}$ ). However, the current HFNEF diagnosis relies exclusively on parameters obtained under resting conditions. This means that patients with heart failure symptomatology and the presence of diastolic dysfunction limited only to exercise may remain undiagnosed. 


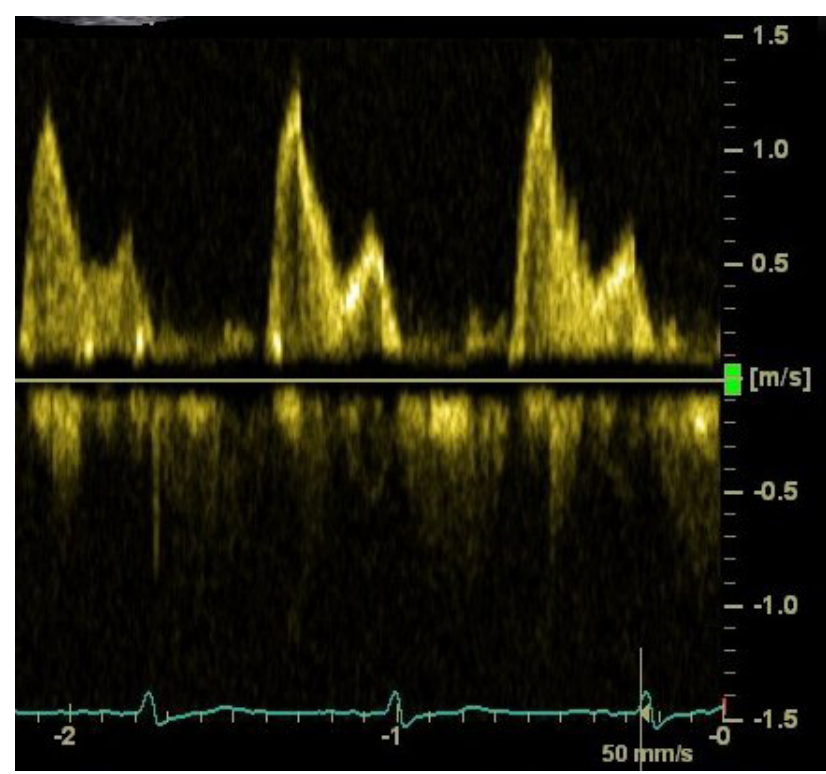

Fig. 1. Doppler recording of transmitral left ventricular filling flow. Two positive waves occur during each R-R interval on electrocardiogram. The first (higher) wave represents the early diastolic transmitral filling flow (E wave), the second wave represents the transmitral flow during atrial contraction (late filling, A wave).

\section{PREVALENCE AND CLINICAL IMPORTANCE OF ISOLATED, ONLY EXERCISE-INDUCED HEART FAILURE WITH NORMAL EJECTION FRACTION}

To date, the prevalence of isolated, only exerciseinduced HFNEF has not been systematically studied. However, several reports suggest that such patients may represent a significant proportion of those with unexplained exertional dyspnea or fatigue. Holland et al. ${ }^{7}$ studied 436 patients with fatigue or dyspnea using exercise echocardiography. None had a significant valvular heart disease or LVEF $<50 \%$. Two hundred and eighty-eight subjects did not fulfill the European Society of Cardiology (ESC) diagnostic HFNEF criteria. Of these, 39 patients (14\%) had exercise $\mathrm{E} / \mathrm{e}^{\prime}>13$ indicative of a significant exercise LVFP elevation. The authors concluded that exercise echocardiography is a valuable tool for identifying patients with impaired functional capacity and raised LVFP. Ha et al. ${ }^{8}$ studied 45 patients with exertional dyspnea and LVEF > 50\% with diastolic stress echocardiography. Of the 26 patients with normal E/e' at rest, 9 (35\%) exhibited $\mathrm{E} / \mathrm{e}^{\prime}$ elevation during exercise that was accompanied by a low exercise tolerance. Meluzin et al. ${ }^{9}$ investigated 84 patients with exertional dyspnea, normal spirometry and LVEF $\geq 50 \%$ using exercise echocardiography. Of the 30 patients with evidence of HFNEF, 6 (20\%) had only exercise-induced HFNEF. In an invasive study of patients after orthotopic heart transplantation with normal LVEF, the same group of researchers ${ }^{10}$ analyzed the response of pulmonary capillary wedge pressure (PCWP) to submaximal exercise. Of the 81 patients, $21(26 \%)$ had no evidence of HFNEF (PCWP at rest $<15 \mathrm{mmHg}$, maximal PCWP

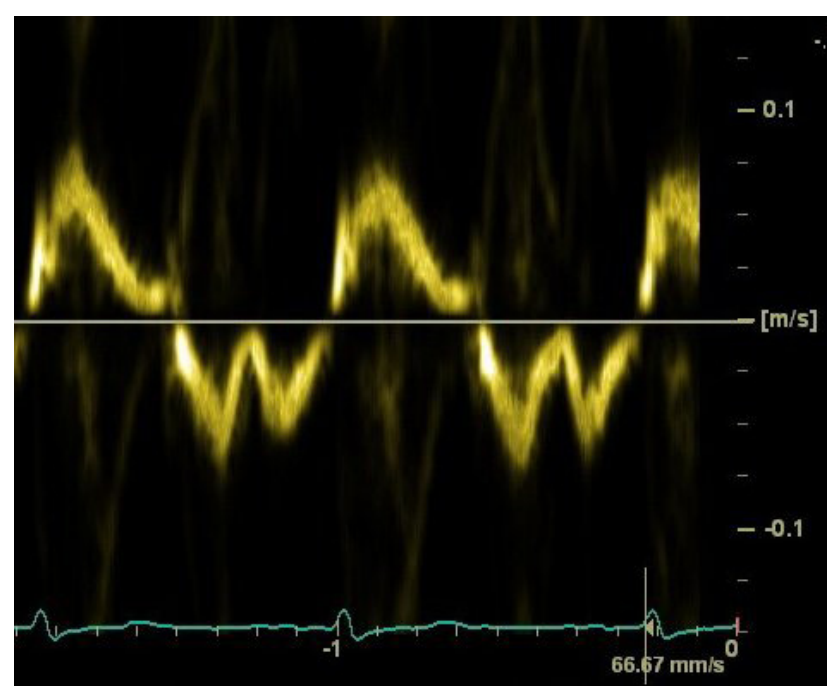

Fig. 2. Doppler recording of mitral annular motion at the septal corner. Four waves occur during each R-R interval on electrocardiogram. Two positive nearly fused waves depict mitral annular motion during isometric and isotonic left ventricular contraction. They are followed by two negatives waves. The first negative wave represents mitral annular motion during early diastole ( $\left.\mathrm{e}^{\prime}\right)$, while the second negative wave represents mitral annular motion during atrial contraction $\left(a^{\prime}\right)$.

during exercise $<25 \mathrm{mmHg}$ ), 13 (16\%) had HFNEF even at rest (PCWP $\geq 15 \mathrm{mmHg}$ at rest), and 47 (58\%) subjects suffered from only exercise-induced HFNEF (PCWP at rest $<15 \mathrm{mmHg}$, maximal PCWP during exercise $\geq$ $25 \mathrm{mmHg}$ ). In another invasive study, Borlaug et al. ${ }^{11}$ examined patients with exertional dyspnea and LVEF > $50 \%$ using right heart catheterization with PCWP measurement. Fifty-five patients with normal brain natriuretic peptide assay, no significant coronary artery disease, and normal resting hemodynamics (PCWP $<15 \mathrm{mmHg}$, mean pulmonary artery pressure $<25 \mathrm{mmHg}$ ) underwent exercise. Thirty-two (58\%) patients were classified as having exercise-induced HFNEF (exercise PCWP $\geq 25 \mathrm{mmHg}$ ), while the remaining subjects had noncardiac dyspnea. In summary, a significant proportion of patients with exertional dyspnea require exercise to diagnose HFNEF.

\section{NONINVASIVE PREDICTION OF LEFT VENTRICULAR FILLING PRESSURE ELEVATION DURING EXERCISE BASED ON ECHOCARDIOGRAPHY}

Under resting conditions, the $\mathrm{E} / \mathrm{e}^{\prime}$ ratio derived from Doppler echocardiograpy is the main noninvasive parameter utilized in clinical practice to diagnose LVFP elevation. However, limited and contradictory data are available concerning the ability of $\mathrm{E} / \mathrm{e}^{\prime}$ to predict LVFP during exercise. In a small study of 12 patients, who presented with dyspnea and LVEF > 50\%, Talreja et al. ${ }^{12}$ found $89 \%$ sensitivity of an $\mathrm{E} / \mathrm{e}^{\prime} \leq 15$ as a predictor for a normal PCWP during exercise. Conversely, in all patients where the E/e' ratio was greater than 15 , the exercise PCWP 
was elevated. Burgess et al. ${ }^{13}$ tested the relationship of $\mathrm{E} / \mathrm{e}^{\prime}$ and LV diastolic pressure (LVDP) during exercise in 37 patients undergoing left heart catheterization. There was a moderate correlation between E/e' and LVDP ( $\mathrm{r}$ $=0.59)$. An exercise $\mathrm{E} / \mathrm{e}^{\prime}>13$ had a sensitivity of $73 \%$ and a specificity of $96 \%$ for identification of an elevated exercise mean LVDP (> $15 \mathrm{mmHg}$ ). When interpreting these results, however, one must take into account the fact that three quarters of patients had significant obstructive coronary artery disease from coronary angiography and $16 \%$ of patients had LVEF $<45 \%$. Thus, ischemic exercise response may have affected the relationship of exercise E/e' and LVDP. Meluzin et al. ${ }^{14}$ studied the accuracy of standard and some new echocardiographic Doppler variables in predicting exercise PCWP elevation $(\geq 25$ $\mathrm{mmHg}$ ) in patients after orthotopic heart transplantation, who were free of post-heart transplant angina pectoris or myocardial infarction, and were found to have LVEF $\geq$ $50 \%$. In 50 subjects with a normal PCWP at rest, exercise $\mathrm{E} / \mathrm{e}^{\prime} \geq 8.5$ predicted exercise $\mathrm{PCWP} \geq 25 \mathrm{mmHg}$ with a sensitivity of $64 \%$ and a specificity of $84 \%$ (area under the curve /AUC/ 0.74). A comparable or slightly better prediction was achieved by exercise E/peak systolic mitral annular velocity $\left(\mathrm{s}^{\prime}\right) \geq 11.0$ (sensitivity $79 \%$, specificity $58 \%$, AUC 0.75) and exercise E/LV systolic longitudinal strain rate $(\mathrm{SR}-\mathrm{S}) \leq-105 \mathrm{~cm}$ (sensitivity $79 \%$, specificity $79 \%$, AUC 0.87). A combination of exercise $\mathrm{E} / \mathrm{e}^{\prime}$ and $\mathrm{E} / \mathrm{s}^{\prime}$ exhibited a trend towards a more precise prediction (AUC 0.78 ) when compared with either variable alone. Even if AUC was maximal for E/SR-S, its clinical applicability was limited, because only $72 \%$ of the subjects had echocardiographic images of adequate quality for exercise strain rate measurements based on speckle tracking technique. Predicting powers of post-exercise plasma levels of brain natriuretic peptide (AUC 0.68) and of N-terminal segment of proatrial natriuretic peptide (AUC 0.72) were somewhat worse than that of exercise $\mathrm{E} / \mathrm{e}^{\prime}$. However, it is unclear whether the results of this study can be applied to other cohorts of patients suspected of having exercise HFNEF. In 28 patients with aortic stenosis, Dalsgaard et al. ${ }^{15}$ showed that exercise-induced changes in E/e' did not correlate with changes in PCWP during exercise. The authors concluded that E/e' cannot be used to detect exercise-induced changes in PCWP in patients with severe aortic stenosis. In a small study of 14 patients with HFNEF, Maeder et al. ${ }^{16}$ also found no relationship between E/e' and PCWP during exercise. During exercise, there was a similar increase in $\mathrm{E}$ and $\mathrm{e}^{\prime}$ in both HFNEF patients and controls and peak exercise E/e' did not significantly differ between patients and controls. Andersen et al. ${ }^{17}$ studied 61 post myocardial infarction patients with LVEF $\geq 45 \%$ and mild-to-moderate diastolic dysfunction at rest using simultaneous exercise echocardiography and right heart catheterization. The changes in $\mathrm{E} / \mathrm{e}^{\prime}$ did not reflect changes in PCWP with exercise. Even if PCWP rose from $13 \pm 4 \mathrm{mmHg}$ at rest to $33 \pm 8 \mathrm{mmHg}$ at peak exercise, simultaneously measured $\mathrm{E} / \mathrm{e}^{\prime}$ decreased from 10.5 \pm 1.7 to $9.3 \pm 2.3$. There was no correlation between $\mathrm{E} / \mathrm{e}^{\prime}$ and PCWP either at rest $(\mathrm{r}=0.20, P=0.12)$ or at peak exercise $(\mathrm{r}=0.16, P=0.24)$, and only a weak correlation between E/e' and PCWP at submaximal exercise $(r=0.26$, $P=0.05$ ). Similarly, correlations of the other echocardiographic Doppler parameters with PCWP at submaximal and peak exercise were poor. The most likely explanation for these discrepancies are different populations used to examine the relationships of exercise LVFP and exercise echocardiographic parameters (populations with various structural myocardial changes accounting for increased myocardial stiffness, differences in afterload and preload, possible effects of exercise-induced ischemia and of regional wall motion abnormalities in some studies, in postheart transplant patients the influence of post-transplant vasculopathy, myocardial rejection, or left atrial structural and functional changes). Recently, the inability to predict noninvasively changes in LVFP during exercise was also demonstrated in patients with LV systolic dysfunction ${ }^{18}$. In this study, the exercise-induced PCWP elevation was not reflected in an increase in $\mathrm{E} / \mathrm{e}^{\prime}$.

Therefore, it is unclear, whether the $\mathrm{E} / \mathrm{e}^{\prime}$ ratio or any other parameters derived from echocardiography can be used to diagnose exercise-induced LVFP elevation and exercise-induced HFNEF. Rather than individual parameters alone, combinations of standard and optimally even new noninvasive parameters may result in success.

\section{LIMITATIONS OF THE CURRENTLY USED ECHOCARDIOGRAPHIC METHODS AND PARAMETERS}

There are several limitations of pulsed-wave Doppler transmitral flow velocity and tissue Doppler mitral annular velocity parameters in assessing exercise HFNEF and in predicting exercise-induced LVFP elevation. Some obstacles are related to the methodology of parameter acquisition, others are inherent in Doppler variables. From the methodological viewpoint, echocardiographic measures can be obtained either during exercise or shortly after exercise. Acquisition of Doppler parameters during exercise is difficult due to exaggerated heart motion and the presence of breathing artifacts. Post-exercise acquisition of Doppler data may affect $E$ and $e^{\prime}$ values and artificially decrease the $\mathrm{E} / \mathrm{e}^{\prime}$ ratio in patients with rapid recovery of exerice-induced diastolic dysfunction. Meluzin et al. ${ }^{19}$ described normalization of exercise-induced elevation in PCWP within the first post-exercise minute in $13.7 \%$ of patients. Rapid post-exercise PCWP recovery within 2 minutes was achieved in $35.3 \%$ of patients. Therefore, short-lasting post-exercise LVFP elevation may not be fully reflected in E/e' obtained even during the immediate post-exercise period.

Concerning limitations inherent in Doppler echocardiography, it is important to take into account that Doppler-derived parameters are influenced by many factors other than diastolic dysfunction. Transmitral early filling velocity (E) is influenced not only by left atrial pressure, LV relaxation and intrinsic myocardial stiffness, but also by LV systolic function ${ }^{20,21}$, afterload, preload ${ }^{22}$, body mass index ${ }^{23}$, sympathetic stimulation and parasympathetic withdrawal ${ }^{24}$, etc. Similarly, e' is not exclusively in- 
fluenced by LV relaxation, but is also preload dependent ${ }^{25}$, even if to a lesser degree compared to $\mathrm{E}\left(\right.$ ref. $\left.^{26}\right) \mathrm{e}^{\mathrm{e}}$ was also found to be related to body mass index ${ }^{23}$, afterload ${ }^{27}, \mathrm{LV}$ long-axis systolic function ${ }^{28}$, and age ${ }^{29,30}$. Borlaug et al. ${ }^{27}$ demonstrated that $\mathrm{e}^{\prime}$ is inversely associated with vascular load, which is mediated predominantly by an increase in arterial stiffness. In a very carefully designed experimental study, Opdahl et al. ${ }^{31}$ revealed independent contributions of LV relaxation, restoring forces, and lengthening load to LV early diastolic lengthening velocity. The E/e' ratio, which is clinically used to estimate noninvasively LVFP, is also influenced by body mass index ${ }^{23}$, afterload ${ }^{27}$, and age $^{30}$. The effect of body mass index on $\mathrm{E} / \mathrm{e}^{\prime}$ is independent of factors influencing LV diastolic function ${ }^{23}$. De Sutter et al. ${ }^{30}$ described a strong age-dependence of the $\mathrm{E} / \mathrm{e}^{\prime}$ ratio and suggested to define normal cutoff $\mathrm{E} / \mathrm{e}^{\prime} \mathrm{val}$ ues for different age cathegories.

In summary, both $E$ and $e^{\prime}$ are influenced by many factors comprising not only diastolic properties of the left ventricle, but also LV systolic function, hemodynamic factors, and factors extrinsic to the left ventricle. Their contribution to LVFP elevation may vary in individual patients making prediction of exercise LVFP elevation based on Doppler-derived variables difficult. In addition, it is unclear whether various factors with a capacity to modify the $\mathrm{E} / \mathrm{e}^{\prime}$ ratio have the identical influence on LVFP measured invasively.

\section{OTHER HEMODYNAMIC AND FUNCTIONAL ABNORMALITIES WITH POTENTIAL TO CONTRIBUTE TO THE DIAGNOSIS OF EXERCISE HEART FAILURE WITH NORMAL EJECTION FRACTION}

Apart from the E/e' ratio, there are other parameters that may have a potential to indicate exercise-induced diastolic dysfunction or other disturbances associated with HFNEF. Tan et al. ${ }^{32}$ analyzed response to exercise in 56 patients with HFNEF. Compared to 27 age-matched healthy controls, subjects with heart failure had significantly lower mitral annular velocities in systole ( $\left.\mathrm{s}^{\prime}\right)$ and early diastole ( $\left.\mathrm{e}^{\prime}\right)$, as well as global longitudinal and radial strain, apical rotation, untwist rate, both at rest and during exercise. On exercise, the differences in s' and e' became even more apparent. The results of this study suggest lower systolic and diastolic longitudinal reserve in HFNEF patients. Borlaug et al. ${ }^{33}$ compared exercise hemodynamics in 21 patients with HFNEF, 19 subjects with hypertension without heart failure and in 10 controls. Patients with HFNEF had blunted exercise-induced increases in chronotropy, contractility, and vasodilation which resulted in impaired ventricular-arterial coupling responses during exercise. Similar results were found in another study population of 17 patients with HFNEF (ref. ${ }^{34}$ ). These studies highlighted the depressed reserve capacity involving multiple domains of cardiovascular function in patients with HFNEF. Donal et al. ${ }^{35}$ compared differences in hemodynamic and functional response to exercise between 21 patients with HFNEF and 15 controls. Increments in heart rate and $\mathrm{e}^{\prime}$ were higher in controls than those in HFNEF patients. Many parameters, including s', e', global longitudinal and circumferential strain, right ventricular annular velocities in systole and early diastole, end-systolic elastance, and the ratio of arterial elastance/end-systolic elastance were significantly lower both at rest and during exercise in patients with HFNEF. The usefulness of the measurement of LV longitudinal systolic function was confirmed by Wenzelburger et al. ${ }^{36}$ who found a significantly lower mitral annular plane systolic excursion (MAPSE) at rest and mainly during exercise in 62 subjects with HFNEF compared to 36 control subjects. In HFNEF patients, other authors found significantly higher exercise pulmonary vascular resistance index ${ }^{37}$, systemic vascular resistance index ${ }^{37}$, lower exercise stroke volume index and cardiac index ${ }^{37,38}$, greater arterial stiffening ${ }^{39,40}$, and reduced arteriovenous oxygen difference ${ }^{41,42}$.

In summary, despite many new potentially applicable diagnostic parameters or disturbances associated with exercise HFNEF, none have been sufficiently validated to diagnose exercise HFNEF. The results come from small studies, many disturbances are not specific for exercise HFNEF, no diagnostic cutoff values are known for the majority of parameters studied, and only a minority of noninvasively obtained parameters were related to invasively measured functional and hemodynamic data.

Table 1. Studies on exercise-induced responses of left ventricular filling pressure in control subjects without any evidence of heart failure with normal ejection fraction.

\begin{tabular}{|c|c|c|c|c|}
\hline Authors (References) & Subjects & Parameter & Value at rest $(\mathrm{mmHg})$ & Value during exercise $(\mathrm{mmHg})$ \\
\hline Parker et al..$^{43}$ & 50 & LVEDP & $9 \pm 3($ range, $4-17)$ & $13 \pm 5($ range, $1-24)$ \\
\hline Parker et al. ${ }^{43}$ & 9 & PCWP & $6 \pm 1 * *$ & $13 \pm 1 * *$ \\
\hline Okada et al. ${ }^{44}$ & 9 & PCWP & $7.2 \pm 3.0$ & $3.7 \pm 2.2$ \\
\hline Yoshida et al. ${ }^{45}$ & 5 & PCWP & $10.0 \pm 1.9$ & $16.2 \pm 4.0$ \\
\hline Nonogi et al. ${ }^{46}$ & 9 & LVEDP & $10 \pm 3(19 \pm 5)^{*}$ & $19 \pm 5$ \\
\hline Maeder et al. ${ }^{16}$ & 8 & PCWP & $10 \pm 4$ & $20 \pm 7$ \\
\hline Borlaug et al. ${ }^{11}$ & 23 & PCWP & $9 \pm 3$ & $11 \pm 5$ \\
\hline
\end{tabular}




\section{WHAT IS A NORMAL EXERCISE-INDUCED ELEVATION IN LEFT VENTRICULAR FILLING PRESSURE?}

In view of the key role of the determination of LVFP elevation for the diagnosis of HFNEF, the definition of normal LVFP reaction to exerice is of utmost importance. In this regard, however, large discrepancies exist in reports published thus far. Table 1 summarizes some resting and exercise data in healthy controls and patients with noncardiac symptoms exercising in a supine position. Based on these studies, it is really difficult to define a normal reaction of LVFP to exercise or to determine any exact cutoff value separating normal and abnormal exercise LVFP.

\section{CONCLUSION}

The current establishment of a diagnosis of exerciseinduced HFNEF is associated with difficulties and controversies that make it difficult and still unsatisfactory. Conclusions derived from noninvasive studies are based on small and mostly single-center studies that frequently provide contradictory results. Echocardiographic, mainly Doppler-derived parameters that are most frequently used to diagnose exercise HFNEF have numerous limitations. Even invasive studies on LV diastolic function during exercise are associated with problems in the interpretation of the obtained data because there is no agreement concerning the cutoff values separating normal and abnormal exercise values. More data and probably new diagnostic approaches are necessary to reliably diagnose exercise HFNEF.

\section{ABBREVIATIONS}

AUC, Area under the curve; E, Early diastolic transmitral flow velocity; e', Early diastolic mitral annular velocity; HFNEF, Heart failure with normal ejection fraction; LVDP, Left ventricular diastolic pressure; LVEF, Left ventricular ejection fraction; LVFP, Left ventricular filling pressure; PCWP, Pulmonary capillary wedge pressure; SR-S, Systolic longitudinal strain rate.

Acknowledgement: The study was supported in part by the European Regional Development Fund - Project FNUSA-ICRC (No. CZ.1.05/1.1.00/02.0123).

Author contributions: JM, ZG, MS: literature search, manuscript writing and revising, final approval; RP: manuscript writing and revising, final approval.

Conflict of interest statement: None declared.

\section{REFERENCES}

1. McMurray JJV, Adamopoulos S, Anker SD, Auricchio A, Böhm M, Dickstein K, Falk V, Filippatos G, Fonseca C, Gomez-Sanches MA, Jaarsma T, Kober L, Lip GYH, Maggioni AP, Parkhomenko A, Pieske BM, Popescu BA, Ronnevik PK, Rutten FH, Schwitter J, Seferovic
P, Stepinska J, Trindade PT, Voors AA, Zannad F, Zeiher A. ESC Guidelines for the diagnosis and treatment of acute and chronic heart failure 2012. Eur Heart J 2012;33:1787-847.

2. Redfield MM, Jacobsen SJ, Burnett JC, Mahoney DW, Bailey KR, Rodeheffer RJ. Burden of systolic and diastolic ventricular dysfunction in the community. Appreciating the scope of the heart failure epidemic. JAMA 2003;289:194-202.

3. Bhatia RS, Tu JV, Lee DS, Austin PC, Fang J, Haouzi A, Gong Y, and Liu PP. Outcome of heart failure with preserved ejection fraction in a population-based study. N Engl J Med 2006;355:260-9.

4. Owan TE, Hodge DO, Herges RM, Jacobsen SJ, Roger VL, Redfield MM. Trends in prevalence and outcome of heart failure with preserved ejection fraction. N Engl J Med 2006;355:251-9.

5. Steinberg BA, Zhao X, Heidenreich PA, Peterson ED, Bhatt DL, Cannon $\mathrm{ChP}$, Hernandez AF, Fonarow GC. Trends in patients hospitalized with heart failure and preserved left ventricular ejection fraction. Prevalence, therapies, and outcomes. Circulation 2012;126:65-75.

6. Paulus WJ, Tschöpe C, Sanderson JE, Rusconi C, Flachskampf FA, Rademakers FE, Marino P, Smiseth O, De Keulenaer G, Leite-Moreira AF, Borbély A, Édes I, Handoko ML, Heymans S, Pezzali N, Pieske B, Dickstein K, Fraser AG, and Brutsaert DL. How to diagnose diastolic heart failure: a consensus statement on the diagnosis of heart failure with normal left ventricular ejection fraction by the Heart Failure and Echocardiography Associations of the European Society of Cardiology. Eur Heart J 2007;28:2539-50.

7. Holland DJ, Prasad SB, and Marwick TH. Contribution of exercise echocardiography to the diagnosis of heart failure with preserved ejection fraction (HFpEF). Heart 2010;96:1024-8.

8. Ha JW, Oh JK, Pellikka PA, Ommen SR, Stussy VL, Bailey KR, Seward JB, and Tajik AJ. Diastolic stress echocardiography: a novel noninvasive diagnostic test for diastolic dysfunction using supine bicycle exercise Doppler echocardiography. J Am Soc Echocardiogr 2005;18:638.

9. Meluzin J, Sitar J, Kř́ístek J, Prosecký R, Pešl M, Podroužková H, Soška $V$, Panovský $R$, and Dušek L. The role of exercise echocardiography in the diagnostics of heart failure with normal left ventricular ejection fraction. Eur J Echocardiogr 2011;12:591-602.

10. Meluzin J, Hude $P$, Leinveber $P$, Krejci J, Spinarova L, Bedanova $H$ Podrouzkova H, Stepanova R, Nemec P. High prevalence of exerciseinduced heart failure with normal ejection fraction in post-heart transplant patients. Biomed Pap Med Fac Univ Palacky Olomouc Czech Repub 2014;158:295-302.

11. Borlaug BA, Nishimura RA, Sorajja P, Lam CSP, Redfield MM. Exercise hemodynamics enhance diagnosis of early heart failure with preserved ejection fraction. Circ Heart Fail 2010;3:588-95.

12. Talreja DR, Nishimura RA, Oh JK. Estimation of left ventricular filling pressure with exercise by Doppler echocardiography in patients with normal systolic function: a simultaneous echocardiographiccardiac catheterization study. J Am Soc Echocardiogr 2007;20:477-9.

13. Burgess Ml, Jenkins C, Sharman JE, Marwick TH. Diastolic stress echocardiography: hemodynamic validation and clinical significance of estimation of left ventricular filling pressure with exercise. J Am Coll Cardiol 2006;47:1891-900.

14. Meluzin J, Hude P, Krejci J, Spinarova L, Podrouzkova H, Leinveber P, Dused L, Soska V, Tomandl J, Nemec P. Noninvasive prediction of the exercise-induced elevation in left ventricular filling pressure in post-heart transplant patients with normal left ventricular ejection fraction. Exp Clin Cardiol 2013;18:63-72.

15. Dalsgaard M, Kjaergaard J, Pecini R, Iversen KK, Kober L, Moller JE, Grande $\mathrm{P}$, Clemmensen $\mathrm{P}$, and Hassager $\mathrm{Ch}$. Left ventricular filling pressure estimation at rest and during exercise in patients with severe aortic valve stenosis: comparison of echocardiographic and invasive measurements. J Am Soc Echocardiogr 2009;22:343-9.

16. Maeder MT, Thompson BR, Brunner-La Rocca HP, Kaye DM. Hemodynamic basis of exercise limitation in patients with heart failure and normal ejection fraction. J Am Coll Cardiol 2010;56:85563.

17. Andersen MJ, Ersboll M, Gustafsson F, Axelsson A, Hassager Ch, Kober L, Boesgaard S, Pellikka P, Moller JE. Exercise-induced changes in left ventricular filling pressure after myocardial infarction assessed with simultaneous right heart catheterization and Doppler echocardiography. Int J Cardiol 2013;168:2803-10.

18. Marchandise S, Vanoverschelde JL, D'Hondt AM, Gurne $O$, Vancraeynest D, Gerber B, and Pasquet A. Usefulness of tissue 
Doppler imaging to evaluate pulmonary capillary wedge pressure during exercise in patients with reduced left ventricular ejection fraction. Am J Cardiol 2014;113:2036-44.

19. Meluzin J, Hude P, Krejci J, Spinarova L, Leinveber P, Stepanova R, Nemec $P$. Variability of post-exercise pulmonary capillary wedge pressure recovery. Implications for noninvasive echocardiographic diagnostics. Biomed Pap Med Fac Univ Palacky Olomouc Czech Repub 2013. [Epub ahead of print] doi:10.5507/bp.2013.016.

20. Thomas JD, and Weyman AE. Echocardiographic Doppler evaluation of left ventricular diastolic function. Physics and physiology. Circulation 1991;84:977-90.

21. Courtois M, Mechem CJ, Barzilai B, and Ludbrook PA. Factors related to end-systolic volume are important determinants of peak early diastolic transmitral flow velocity. Circulation 1992;85:1132-8.

22. Triulzi MO, Castini D, Ornaghi M, and Vitolo E. Effects of preload reduction on mitral flow velocity pattern in normal subjects. Am Cardiol 1990;66:995-1001.

23. Russo C, Jin Z, Homma S, Rundek T, Elkind MSV, Sacco RL, Di Tullio MR. Effects of obesity and overweight on left ventricular diastolic function. J Am Coll Cardiol 2011;57:1368-74.

24. Johannessen KA, Cerqueira M, Veith RC, Stratton JR. Influence of sympathetic stimulation and parasympathetic withdrawal on Doppler echocardiographic left ventricular diastolic filling velocities in young normal subjects. Am J Cardiol 1991;67:520-6.

25. Drighil A, Madias JE, Mathewson JW, Mosalami HE, Badaoui NE, Ramdani B, and Bennis A. Haemodialysis: effects of acute decrease in preload on tissue Doppler imaging indices of systolic and diastolic function of the left and right ventricles. Eur J Echocardiogr 2008;9:530-5.

26. Agmon Y, Oh JK, McCarthy JT, Khandheria BK, Bailey KR, and Seward $J B$. Effect of volume reduction on mitral annular diastolic velocities in hemodialysis patients. Am J Cardiol 2000;85:665-8.

27. Borlaug BA, Melenovsky V, Redfield MM, Kessler K, Chang HJ, Abraham TP, Kass DA. Impact of arterial load and loading sequence on left ventricular tissue velocities in humans. J Am Coll Cardio 2007;50:1570-7.

28. Popovic ZB, Desai MY, Buakhamsri A, Puntawagkoon Ch, Borowski A Levine BD, Tang WWH, and Thomas JD. Predictors of mitral annulus early diastolic velocity: impact of long-axis function, ventricular filling pattern, and relaxation. Eur J Echocardiogr 2011;12:818-25.

29. Alam M, Wardell J, Andersson E, Samad BA, and Nordlander R. Characteristics of mitral and tricuspid annular velocities determined by pulsed wave Doppler tissue imaging in healthy subjects. J Am Soc Echocardiogr 1999;12:618-28.

30. De Sutter J, De Backer J, Van de Veire N, Velghe A, De Buyzere M, and Gillebert TC. Effects of age, gender, and left ventricular mass on septal mitral annulus velocity (E') and the ratio of transmitral early peak velocity to E' (E/E'). Am J Cardiol 2005;95:1020-3.

31. Opdahl A, Remme EW, Helle-Valle T, Lyseggen E, Vartdal T, Pettersen E, Edvardsen T, Smiseth OA. Determinants of left ventricular earlydiastolic lengthening velocity. Independent contributions from left ventricular relaxation, restoring forces, and lengthening load. Circulation 2009;119:2578-86.

32. Tan YT, Wenzelburger F, Lee E, Heatlie G, Leyva F, Patel K, Frenneaux $M$, Sanderson JE. The pathophysiology of heart failure with normal ejection fraction. Exercise echocardiography reveals complex abnormalities of both systolic and diastolic ventricular function involving torsion, untwist, and longitudinal motion. J Am Coll Cardiol 2009;54:36-46.
33. Borlaug BA, Olson TP, Lam CSP, Flood KS, Lerman A, Johnson BD, Redfield MM. Global cardiovascular reserve dysfunction in heart failure with preserved ejection fraction. J Am Coll Cardiol 2010;56:84554.

34. Borlaug BA, Melenovsky V, Russell SD, Kessler K, Pacak K, Becker LC, Kass DA. Impaired chronotropic and vasodilator reserves limit exercise capacity in patients with heart failure and a preserved ejection fraction. Circulation 2006;114:2138-47.

35. Donal E, Thebault Ch, Lund LH, Kervio G, Reynaud A, Simon T, Drouet $\mathrm{E}$, Nonotte $\mathrm{E}$, Linde $\mathrm{C}$, and Daubert JC. Heart failure with a preserved ejection fraction additive value of an exercise stress echocardiography. Eur Heart J Cardiovasc Imaging 2012;13:656-65.

36. Wenzelburger FWG, Tan YT, Choudhary FJ, Lee ESP, Leyva F, and Sanderson JE. Mitral annular plane systolic excursion on exercise: a simple diagnostic tool for heart failure with preserved ejection fraction. Eur J Heart Fail 2011;13:953-60.

37. Maeder MT, Thompson BR, Htun N, and Kaye DM. Hemodynamic determinants of the abnormal cardiopulmonary exercise response in heart failure with preserved left ventricular ejection fraction. J Card Fail 2012;18:702-10.

38. Kitzman DW, Higginbotham MB, Cobb FR, Sheikh KH, Sullivan MJ. Exercise intolerance in patients with heart failure and preserved left ventricular systolic function: failure of the Frank-Starling mechanism. J Am Coll Cardiol 1991;17:1065-72.

39. Ennezat $P V$, Lefetz $Y$, Maréchaux $S$, Six-Carpentier $M$, Deklunder G, Montaigne D, Bauchart JJ, Mounier-Véhier C, Jude B, Neviere R, Bauters Ch, Asseman P, De Groote P, and Lejemtel TH.. Left ventricular abnormal response during dynamic exercise in patients with heart failure and preserved left ventricular ejection fraction at rest. J Card Fail 2008;14:475-80.

40. Tartiere-Kesri L, Tartiere JM, Logeart D, Beauvais F, Solal AC. Increased proximal arterial stiffness and cardiac response with moderate exercise in patients with heart failure and preserved ejection fraction. J Am Coll Cardiol 2012;59:455-61.

41. Haykowsky MJ, Brubaker PH, John JM, Stewart KP, Morgan TM, Kitzman DW. Determinants of exercise intolerance in elderly heart failure patients with preserved ejection fraction. J Am Coll Cardiol 2011;58:265-74.

42. Bhella PS, Prasad A, Heinicke K, Hastings JL, Arbab-Zadeh A, AdamsHuet B, Pacini EL, Shibata S, Palmer MD, Newcomer BR, and Levine $\mathrm{BD}$. Abnormal haemodynamic response to exercise in heart failure with preserved ejection fraction. Eur J Heart Fail 2011;13:1296-304.

43. Parker JO, Thadani U. Cardiac performance at rest and during exercise in normal subjects. Bull. europ. Physiopath. resp. 1979;15:93549.

44. Okada RD, Osbakken MD, Boucher ChA, Strauss HW, Block PC, and Pohost GM. Pulmonary blood volume ratio response to exercise: a noninvasive determination of exercise-induced changes in pulmonary capillary wedge pressure. Circulation 1982;65:126-33.

45. Yoshida A, Kadota K, Kambara H, Tamaki S, Suzuki Y, Kawai Ch, Tamaki N, and Torizuka K. Left ventricular responses to supine bicycle exercise assessed by radionuclide angiography and a SwanGanz catheter. Jap Circ J 1985;49:661-71.

46. Nonogi H, Hess OM, Ritter M, Krayenbuehl HP. Diastolic properties of the normal left ventricle during supine exercise. Br Heart J 1988;60:30-8. 